ISSN: $1130-3743$

DOI: http://dx.doi.org/10.14201/teoredu20152716984

\title{
EXPLORACIÓN DE NUEVAS VÍAS DE CONSTRUCCIÓN MEDIÁTICA DE LA CIUDADANÍA EN LA ESCUELA: DE ANTÍGONA A LA NARRATIVA TRANSMEDIA
}

\section{Exploring new ways of media construction of citizenship in schools: from Antigone to transmedia storytelling}

\section{Exploration de nouvelles voies de construction médiatique de la citoyenneté à l'école: d'Antigone à la narrative transmédia}

Gonzalo Jover*, María del Rosario GONZÁlez MARTín* y Juan Luis FuENTE***

* Universidad Complutense de Madrid. Facultad de Educación. Departamento de Teoría e Historia de la Educación. C/ Rector Royo Villanova, s/n. 28040 Madrid. gjover@ucm.es; marrgonz@ucm.es

** Universidad Internacional de La Rioja. Facultad de Educación. Gran Via del Rey Juan Carlos I, 41. 26002 Logroño, La Rioja.juanluis.fuentes@unir.net

Fecha de recepción: enero de 2015

Fecha de aceptación: abril de 2015

Biblid [(1130-3743) 27, 1-2015, 69-84]

\section{RESUMEN}

Los recientes movimientos de participación ciudadana han encontrado en Internet y en las redes sociales virtuales un entorno propicio para su desarrollo, lo que debe suscitar la reflexión pedagógica sobre sus posibilidades en la educación para la ciudadanía. Este artículo presenta las bases teóricas y puesta en práctica piloto de una propuesta de trabajo escolar que permita avanzar hacia un concepto de alfabetización digital que incluya tanto la competencia digital como la competencia cívica. 
Partiendo de la obra clásica Antígona, concebida como el primer gesto de desobediencia civil, se exploran las categorías de lo público y lo privado, en cuya narración se perciben como ámbitos enfrentados, y se plantea entender la escuela como un espacio que encarne la experiencia de conversación entre estos dos ámbitos. Para ello, el proyecto propone aunar la capacidad provocadora de la literatura clásica y las potencialidades de las narrativas transmedia, de modo que los estudiantes dejen de ser meros consumidores de recursos tecnológicos para convertirse en autores críticos frente a la realidad que les rodea.

Palabras clave: Educación para la ciudadanía; Tecnologías de la Información y la Comunicación; Espacio público; Espacio privado; narrativas transmedia.

\section{SUMMARY}

Recent movements of citizen participation have found on the Internet and the Social Networks a favorable environment for development, which should lead us to a pedagogical reflection about the potential of virtual spaces for citizenship education. This article presents the theoretical basis and the pilot project of a school work which allows us to promote a concept of digital literacy that includes digital and civic competence. From the classic Antigone, conceived as the first act of civil disobedience, we explore the categories of public and private, which are perceived on this narration as opposite areas. Then we propose to understand the school as a space of conversation between both contexts. For this task, the project brings together the provocative capacity of classic literature and the potential of transmedia storytelling, where pupils are not only consumers but also critical participants before the social reality.

Key words: Citizenship education; Information and Communication Technologies; Public Space; Private Space; Transmedia Storytelling.

\section{SOMMAIRE}

Les nouveaux mouvements de participation des citoyens ont trouvé à Internet et aux réseaux sociaux virtuelles un environnement favorable pour son développement. Ça doit susciter la réflexion pédagogique sur leurs chances dans l'éducation pour la citoyenneté. Cet article présente les bases théoriques et la mise en pratique pilote d'une propose de travail scolaire qui permet faire des progrès vers un concept d'alphabétisation digital inclusive, le quel vise à la fois la compétence digital et la compétence civique. À partir de l'œuvre classique Antigone, conçue comme le premier geste de désobéissance civil, on explore les catégories du public et le privé, les quels à la narration sont perçus comme domaines confrontés, et on essaie de comprendre l'école comme un espace qu'incarne l'expérience de conversation entre ces deux domaines. Pour ça, le projet propose joindre la capacité de provocation de la littérature classique et las potentialités des narratives transmédia, afin que les 
GONZALO JOVER, M. ${ }^{a}$ DEL ROSARIO GONZÁLEZ MARTÍN Y JUAN LUIS FUENTES

étudiants cessent d'être des simples consommateurs de ressources technologiques et deviennent auteurs critiques face à la réalité autour d'eux.

Mots clés: Éducation à la citoyenneté; technologies de l'information et de la communication; l'espace public; espace privé; récits transmedia.

\section{INTRODUCCIÓN ${ }^{1}$}

Este artículo presenta las bases teóricas y la experiencia piloto de una propuesta de trabajo de educación para la ciudadanía en la escuela. Basado en la lectura y reescritura de la tragedia clásica Antígona a través de la narrativa transmedia, permite apreciar las posibilidades de diálogo entre los criterios éticos particulares de la vida privada y las normas institucionalizadas de la esfera pública, en gran parte enfrentados en la discusión sociopolítica actual.

La incursión de las Tecnologías de la Información y la Comunicación en las sociedades actuales está motivando una redefinición de ciertas categorías de pensamiento, desde la educación y el derecho, hasta el ejercicio de la ciudadanía. A pesar de los ingenuos mitos establecidos y las visiones ciberutópicas, la democracia como noción no es ajena a la influencia emancipadora de Internet (Innerarity, 2012; Morozov, 2012), y cada vez son más las vías que se abren para la promoción de la participación ciudadana. La Revolución Twitter en los países con sistemas dictatoriales, las oficinas virtuales de las administraciones públicas en los Estados modernos o las iniciativas sociales de convocatorias variadas encuentran en el entorno virtual un fértil lugar de acomodo.

La actual generación de nativos digitales ha adoptado un papel protagonista en estos movimientos, desmintiendo las acusaciones de falta de compromiso social y político y desinterés por lo público. Las prestaciones de la web 2.0 han contribuido a este cambio al trocar el papel del internauta de mero receptor y consumidor de información al de productor y creador de noticias, historias, interacciones, contenidos audiovisuales, etc. También, es posible que pueda hacer trocar al individuo aislado y apático ante el Estado en un ciudadano protagonista de la vida pública, capaz de opinar y crear opinión, argumentar, proponer, generar redes y movimientos sociales y políticos. Sin embargo, la famosa clasificación de Prensky (2001) de nativos e inmigrantes digitales resulta simplista si se asocia necesariamente la competencia digital con la competencia cívica, dejando desatendidas las necesidades formativas de los adolescentes en cuanto a las diversas formas de articular la participación ciudadana. Además, la competencia mediática también está aún insuficientemente atendida por los currículos escolares (Ramírez García, Renés Arellano y García Ruiz, 2014) y su articulación apenas suele tocar

1. Este artículo forma parte de la investigación desarrollada en el marco del Proyecto "Fundamentos filosóficos de la idea de solidaridad: amor, amistad y generosidad", de referencia FFI2012-37670 del Ministerio de Economía y Competitividad. 
dimensiones fundamentales de carácter ético social implicadas en el ejercicio de la ciudadanía, como la libertad de expresión, la responsabilidad, el pluralismo, el diálogo intercultural y la justicia social (UNESCO, 2011).

No hemos de obviar que las nociones centrales al debate cívico, como las de lo público y lo privado, son abstractas y difíciles de comprender en edades tempranas, pero su distinción e interrelación es necesaria, más aun si cabe en el contexto contemporáneo que tiende a confundirlas (Dalmau, 2012). En consecuencia, no podemos renunciar a su tratamiento desde la escuela, pues de lo contrario dejaríamos a los jóvenes ciudadanos con herramientas tecnológicas pero sin herramientas conceptuales para analizar y participar en la vida cívica. Para iniciar a los jóvenes ciudadanos en este debate, nuestra propuesta aúna las posibilidades del mundo digital con algo tan clásico como la narración de historias, considerada desde siempre como una herramienta fundamental en la promoción de comportamientos ético-cívicos, tanto en culturas occidentales, incardinadas en las raíces de la Grecia clásica, como orientales (Bai y Cohen, 2014). A través de la literatura, los individuos son capaces de lograr una comprensión más profunda de conceptos abstractos y complejos, de sí mismos y de su entorno cercano (Marchesi, 2007), así como de desarrollar comportamientos prosociales (Noddings, 2009). Concretamente, el efecto catártico de la tragedia ha sido reconocido desde la Retórica aristotélica por su capacidad de conmover y modificar el comportamiento humano. La obra elegida como base de nuestra propuesta ha sido Antígona. La elección se ha basado en los siguientes criterios:

- La posibilidad de ver a través de la obra elementos básicos de cómo entender la moral, la ética y el derecho.

- Su carácter de tragedia y la necesidad de aportar una nueva salida al conflicto que plantea.

- El eje de la trama en la tensión entre las esferas de lo público y de lo privado, que facilita la comprensión de su distinción y el conflicto que se pueda dar entre ellas.

- La facilidad de identificación con los personajes por su gran riqueza de argumentos y caracterización de los mismos.

- La resonancia del conflicto presentado en la obra con situaciones de la actualidad.

Antígona ha sido leída como el primer gesto histórico de desobediencia civil, en este caso en la forma de conflicto entre el poder político, representado por Creonte, y los criterios éticos perennes, basados en los lazos consustanciales de la sangre y la familia, que encarna Antígona. Un conflicto entre lo masculino y lo femenino, el orden político y el ético, la ley y la moral, lo civil y lo religioso, lo público y lo privado (Balló y Pérez, 2012). La obra representa hoy a esa juventud indignada que se ha expresado en diversas partes del mundo, dando lugar a lo que se ha llamado "una de las expresiones de indignación de, posiblemente, la generación más formada de la historia" (Hernández, Robles y Martínez, 2013, 64), 
considerada como un auténtico ejemplo de rebeldía democrática por algunas de las voces más destacadas de nuestro tiempo (Sassen, 2011).

La propuesta de trabajo sobre Antígona que presentamos se sitúa, así, en la línea de construcción de un humanismo digital (Doueihi, 2012). Nuestro propósito es hermanar la literatura clásica con la tecnología moderna de la narrativa transmedia en el contexto de los movimientos sociales actuales, como un ejercicio de posicionamiento y búsqueda de alternativas a los conflictos de poder más clásicos y más presentes en la historia, que son a su vez de máxima actualidad.

\section{ADENTRÁNDONOS EN ANTÍGONA: LA PUGNA ENTRE LO PÚBLICO Y LO PRIVADO}

Como es sabido, Antígona se desarrolla al término del asedio de Los Siete contra Tebas. Polinices, hijo de Edipo, ha luchado contra la ciudad para arrebatar el poder a su hermano Eteocles. En la contienda, los dos hijos de Edipo se dan mutuamente muerte. Creonte decreta que el cuerpo de Polinices quede insepulto, expuesto a la degeneración y relegado a ser pasto de los animales carroñeros. Antígona, hermana de los dos contendientes, se niega a acatar la orden y es capturada al intentar honrar el cuerpo de su hermano. En el momento de la detención, increpa a Creonte en su defensa:

No fue Zeus quien dio ese bando, ni la Justicia que comparte su morada con los dioses infernales definió semejantes leyes entre los hombres. Ni tampoco creía yo que tuvieran tal fuerza tus pregones como para poder transgredir, siendo mortal, las leyes no escritas y firmes de los dioses. Pues su vigencia no viene de ayer ni de hoy, sino de siempre, y nadie sabe desde cuándo aparecieron. De su incumplimiento no iba yo, por temor al capricho de hombre alguno, a recibir castigo entre los dioses. Que iba a morir, ya lo sabía -icómo no!-, aunque tú no lo hubieras prevenido en tu proclama (Sófocles, Antígona, 55).

La obra ha sido objeto de atención de numerosos filósofos, sobre todo desde el siglo XIX, como ilustró George Steiner en su ya clásico tratado sobre la misma (Steiner, 2000). De las diferentes lecturas que ha tenido, el centro con respecto al cual, por afirmación o negación, se sitúan las demás es la de Hegel, quien la consideró «una de las obras de arte más sublimes, en todos los respectos, de todos los tiempos" (Hegel, 1989, 341). En la interpretación de Hegel, las dos partes que forman el núcleo del litigio encarnan una relación basada en sendas verdades unilaterales. En sus Lecciones sobre la Estética, escribió:

La ley pública del estado está en abierto conflicto con el íntimo amor familiar y el deber para con el hermano: la mujer, Antígona, tiene como pathos el interés familiar; Creonte, el hombre, el bienestar de la comunidad. Combatiendo contra la propia ciudad natal, Polinices había caído ante las puertas de Tebas, y Creonte, el soberano, amenaza con la muerte, mediante una ley públicamente difundida, a quien dé el honor de la sepultura a aquel enemigo de la ciudad. Pero Antígona no puede aceptar esa orden, que sólo afecta al bien público del estado, y cumple 
como hermana con el sagrado deber de sepultura por la piedad de su amor hacia su hermano. Invoca entonces la ley de los dioses; pero los dioses que ella venera son los dioses subterráneos del Hades, los internos del sentimiento, del amor, de la sangre, no los dioses de la luz de la vida libre y autoconsciente del pueblo y del estado (ibid., 341-342).

En la dialéctica hegeliana el progreso moral requiere el conflicto entre ambas perspectivas, de modo que ni Antígona puede ser una heroína ni Creonte un tirano. Esta interpretación ha hecho fortuna a lo largo del tiempo, hasta la actualidad. Así, por ejemplo, Martha Nussbaum en su reciente Political Emotions parafrasea a Hegel para concluir que "quien piense con atención acerca de la elección que presenta Antígona, verá que es genuinamente una tragedia: aunque puede haber una elección preferible, no hay "respuesta correcta", porque ambas alternativas contienen serios desaciertos" (Nussbaum, 2013, 269).

No todas las lecturas comparten, sin embargo, esta visión equilibrada de la situación, y en la exculpación hegeliana de Creonte se ha visto, a veces, un recurso de justificación del estatismo (Steiner, 2000, 52-58) o una intención legítima que se contradice a sí misma al ser guiada por la soberbia (Santamaría, 2009, 114). Hannah Arendt, alerta de las seducciones totalitarias, está entre quienes tomaron distancia con respecto a la interpretación exculpatoria. También ella tuvo la tragedia griega y especialmente a Antigona en el punto de mira de su filosofía, pues no sólo se refirió a la misma en diversas ocasiones, sino que en su biblioteca se encuentra un volumen con anotaciones que revelan varias lecturas de la obra (Zappulla, 2011).

Arendt consideró Antígona un excelente recurso para explicar las contradicciones de la edad moderna, en particular el conflicto entre lo público y lo privado. Con respecto a este conflicto, en La condición humana afirma apoyándose en la Paideia de Jaeger:

\begin{abstract}
Según el pensamiento griego, la capacidad del hombre para la organización política no es sólo diferente, sino que se halla en directa oposición a la asociación natural cuyo centro es el hogar (oikia) y la familia. El nacimiento de la ciudadestado -continúa, citando a Jaeger-significó que el hombre recibía "además de su vida privada, una especie de segunda vida, su bios politikos. Ahora todo ciudadano pertenece a dos órdenes de existencia, y hay una tajante distinción entre lo que es suyo (idion) y lo que es comunal (koinon)" (Arendt, 1993, 39).
\end{abstract}

Pues bien, para Arendt el error de Creonte fue, precisamente, confundir estos dos planos, lo que a su juicio se revela con nitidez en los pasajes de la relación con su hijo, Hemón, confusión de la que, sin embargo, la autora alemana salva al personaje femenino. Un análisis de los textos en los que Arendt se refirió a la obra y sus propias anotaciones manuscritas a la misma permite a Silvia Zappulla afirmar:

[Arendt] describe varias veces a Creonte como un tirano, como un hombre que gobierna sin un poder reconocido, mediante el uso de la pura violencia... Mantiene que Creonte es responsable de la confusión entre el derecho público y el privado, 
GONZALO JOVER, M. ${ }^{a}$ DEL ROSARIO GONZÁLEZ MARTÍN Y JUAN LUIS FUENTES

mientras que Antígona no lo es. Creonte, de hecho, gobierna la polis como un pater familias ante litteram (antes de que tal cosa existiese). Trata a los ciudadanos como esclavos o niños incapaces de tomar sus propias decisiones. Habla con violencia; se comporta como un basileus (palabra utilizada por Arendt en sus notas al margen para comentar el personaje), es decir, como una figura política que precede a la llegada de la democracia, en la que radica la conceptuación de Arendt de la esfera pública. Hay un conflicto entre el derecho público y el privado, pero éste no se basa en la reivindicación de Antígona, sino más bien en la de Creonte (Zappulla, 2011, 117).

Arendt proyectó la separación entre lo público y lo privado que expresa Antígona en su conceptuación de la escuela, que ella definió como el lugar de transición entre esos dos planos. La crisis de institución educativa viene provocada por la difuminación, bajo el auge de lo social, de los límites que separan ambos planos, que lleva a confundir la misión de la escuela y a asimilarla sin más al mundo público. "Pero la escuela -dice Arendt- no es el mundo, ni debe pretender serlo, ya que es la institución que interponemos entre el campo privado del hogar y el mundo para que sea posible la transición de la familia al mundo" (Arendt, 1996, 200). La consecuencia que Arendt extrae de esta disociación es que "debemos separar de una manera concluyente la esfera de la educación de otros campos, sobre todo del ámbito vital público, político" (ibid., 207).

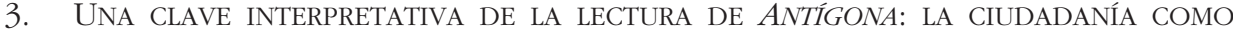 ESPACIO DE CONVERSACIÓN}

Sortear la conclusión a la que llega Arendt exige buscar otras formas de articulación entre lo público y lo privado. Según Judith Butler, la disociación de estas dos esferas impidió a la filósofa alemana comprender la radicalidad de Antígona (Butler, 2001, 108-110). A partir de una revisión de las críticas feministas a la propuesta de Arendt, Sheila Benhabib ha mostrado, sin embargo, las posibilidades que desde su propia filosofía política caben para una reformulación de ambos planos, que los ponga en diálogo sin por ello negarlos o confundirlos, pues su distinción no deja de ser una condición irrenunciable de libertad (Benhabib, 1993, 111). En sus desarrollos más recientes, esta reformulación adopta la forma de lo que Benhabib ha llamado "iteración democrática" como base de una ética de vocación cosmopolita que conjuga la apelación a valores y normas de pretensión universal, como las recogidas en las declaraciones internacionales de derechos humanos, con la atención a los criterios y aspiraciones de las comunidades locales (Benhabib, 2005, 2006, 2011). Tal como las entiende Benhabib, las iteraciones democráticas son formas inacabadas de conversación entre los criterios formales y legales de validez general, propios del mundo público, y las demandas y expectativas que surgen en la sociedad civil, mediante las cuales tanto aquéllos como éstas se reformulan mutuamente. 
Carlo Salzani ha mostrado, en este sentido, como la tragedia de Antígona reside, precisamente, en una ausencia de conversación. A su juicio, lo que la tragedia aporta a la discusión política actual es la posibilidad de un replanteamiento de la idea de comunalidad (commonality). Su interpretación no se centra en la parte de verdad o de mentira que puedan tener Antígona o Creonte, sino en la negación en la obra del espacio de lo común, que revelan las relaciones entre los diversos personajes. Sacar a la luz las consecuencias de esta ausencia es la principal contribución de Antígona como tratado de educación cívica. Señala Salzani:

En la Atenas del siglo v antes de Cristo, la tragedia fue un instrumento político, cuyo objetivo era educar la polis a través de la representación en el escenario de los peligros y problemas de la vida de la comunidad; la cuestión de la comunalidad fue así el tema central de la educación o paideia trágica. La Antígona de Sófocles problematiza y deconstruye esta noción desde casi todos los ángulos posibles: en la relación familiar y la polis, el lenguaje y la comunicación, el amor y la muerte, la naturaleza y la ley. En la obra, cada "figura de comunalidad" es abierta y "diseccionada" para mostrar su fragilidad y sus límites, así como los peligros para la polis cuando se demuelen las "paredes" de su construcción democrática... En Antígona no hay figuras de comunalidad: todas las figuras representan las aberraciones del concepto, que es mostrado, subrayado e invocado haciendo presente su ausencia (Salzani, 2006, 9).

Por esa ausencia, tanto Antígona como Creonte representan interpretaciones erróneas del significado democrático de la ley, al negar ambos sus características fundamentales de deliberación y conciliación fundadas en un logos compartido. En Antígona no hay diálogo sino un conflicto caracterizado por una sucesión de monólogos, rotos sólo por la voz colectiva del coro. La única comunalidad que queda en la tragedia -concluye Salzani- "parece ser la de Antígona con los muertos: ella reniega de cualquier vínculo con la vida y la polis y abraza su destino de muerte. La muerte como única comunalidad posible devora cada comunidad de la obra. Por lo tanto, en Antígona no hay polis, ningún sentido de comunidad, de pluralidad, de democracia: cada cual es apolítico, apartado de la polis por su individualismo, egoísmo o género" (Salzani, 2006, 23).

La idea de lo comunal o procomún se ha instalado también con fuerza como signo de identidad de los actuales movimientos sociales de contestación. Para Chomsky, uno de los grandes logros del movimiento occupy americano fue su constitución, frente a la atomizada sociedad liberal, como entorno de experiencia comunal, en el que las asambleas generales convivían con las bibliotecas y las cocinas (Chomsky, 2012, 56). Y, en España, una de las últimas realizaciones de ciertos grupos asociados al movimiento $15 \mathrm{M}$ ha sido la constitución de una "Fundación de los comunes ${ }^{2}$. Esta derivación es lógica si se tiene en cuenta que el propio mundo del ciberespacio, en el que se instala la acción del movimiento tecnoilustrado de indignación (Jover, Belando-Montoro y Guío, 2014) ha hecho bandera de lo común

2. http://fundaciondeloscomunes.net consultado el 15 de enero de 2014. 
(los commons) como ámbito de creación y difusión del conocimiento, que trasciende la escisión entre lo público y lo privado.

Ahora bien, lo comunal se define tanto por inclusión como por exclusión. El problema con la idea de comunalidad afirmada hoy desde estos movimientos sociales es, paradójicamente, que el debate político se convierta -como sucede en Antígona- en una conversación entre sordos, y que el logos, como factor de identidad interna del grupo, se traduzca de cara al exterior en un monólogo. Como concluye un conocido estudio reciente de Pew Research Center, de Washington, pese a sus promesas de democratización y de apertura de un espacio de conversación sin límites, las redes sociales virtuales no han proporcionado una nueva vía que permita superar la ley de la espiral del silencio, formulada por Elisabeth NoelleNeumann en los años setenta como teoría de la opinión pública. Según esta autora, tenemos cierta tendencia a no manifestar nuestros puntos de vista en un entorno público cuando pensamos que éstos no son ampliamente compartidos. De acuerdo con los resultados de la investigación de Pew Research Center, las nuevas redes de interacción social pueden, de hecho, acentuar más esta tendencia. Los ciudadanos se muestran menos dispuestos a discutir temas políticamente controvertidos en las redes que en los ámbitos de comunicación presencial, y las mismas no suponen una alternativa para quienes son reacios a discutir estos temas en persona, especialmente en aquellos casos en los que perciben que sus opiniones se separan de las de la mayoría (Hampton et al., 2014). Las redes sociales, como espacios de participación cívica, pueden condenar a los ciudadanos al silencio, si no se cuenta con la capacidad de moverse confiadamente, con seguridad y sentido crítico en ellas.

De alguna manera nos enfrentamos en la actualidad al mismo riesgo que presenta Antígona: la ausencia de lo común como espacio de diálogo amplio más allá de los límites de lo comunal. Los monólogos, aunque sean pronunciados por un nosotros, siguen siendo el riesgo de nuestra polis. Es a este punto al que dirigimos nuestra intencionalidad pedagógica de reconstrucción mediática de la ciudadanía a partir de la tragedia griega.

4. DE ANTÍGONA A LA NARRATIVA TRANSMEDIA: UNA PROPUESTA DE EDUCACiÓN PARA LA CIUDADANÍA DESDE «EL ENTRE»

De las premisas anteriores nace la propuesta de un proyecto de educación en la ciudadanía basado en la lectura de Antígona, que dote de contenido la escuela como espacio de experiencia cívica, convirtiéndola del lugar de transición, tierra de nadie, del que hablaba Arendt, en lo que Buber (1981, 141-151) denominó el espacio del "entre", generador de conversación. Dicho de otro modo, se trata de vivir la escuela misma como una situación de "experiencia comunicada conjuntamente", que es como John Dewey definió la democracia (Dewey, 1995, 82). Nuestra propuesta generadora de dicha experiencia comunicativa se concreta en leer y reescribir Antígona, como expresión de conflicto entre lo público y lo privado, a partir de las posibilidades que ofrece la narrativa transmedia. 
El acercamiento a la escuela de la lectura de Antígona supone hacer conscientes a los estudiantes de la capacidad de los clásicos para iluminar el momento actual. Como decía Steiner, la denominación de clásico "significa que se trata de un texto que, en sentido estricto, es inagotable" (Steiner, 2000, 127), en cuanto fuente de inspiración y reflejo para el análisis y la interpretación de los problemas esencialmente humanos. Así pues, cabe concebir los clásicos como parte de una educación para la ciudadanía que descubre en el transcurrir histórico y literario partes de la condición humana y de su ineludible vivir en sociedad.

Si entendemos con Levinas que "el otro es la enseñanza básica", nuestra educación para la ciudadanía no podría estar centrada únicamente en la mirada de lo propio y su relación con el Derecho. No puede centrarse sólo en Antígona y Creonte, tiene que aparecer una nueva forma de mirar el propio problema que surja de la mirada al otro, del reconocimiento de su rostro, incluso de la jerarquización de los problemas al reconocerse como un otro, como uno más entre los otros. Muchas exacerbaciones en la relación entre lo privado y lo público o de su regulación por el Estado se generan por discursos excesivamente autorreferenciales, incapaces de mirar al otro o de situarse como un otro entre los otros. Por ello, resulta fundamental que en un proyecto de educación para la ciudadanía emerja necesariamente el diálogo gestado con el "otro" presente y no con una representación ficticia, a nuestra medida.

La narrativa transmedia se nos presenta como una herramienta educativa capaz de promover estos objetivos. Si bien no fue concebida inicialmente con un propósito pedagógico sino comercial, quien ha sido reconocido como el autor que acuñó este concepto destaca su potencial en el ámbito de la educación (Jenkins, 2010). En pocas palabras, la narrativa transmedia se define como el aprovechamiento de las características de los diferentes medios tecnológicos para contar una historia, adaptando radicalmente la narración a las peculiaridades del medio hasta tal punto que cobra relevancia por sí misma y deja de ser necesaria la referencia a la narrativa original para su comprensión. De esta forma, cada narrativa deja de ser dependiente de las otras para convertirse en una experiencia complementaria.

Las TIC multiplican las posibilidades de la transmediación poniendo a disposición del usuario variados formatos de acceso a las narraciones. El libro tradicional se complementa con webs que incluyen textos, sonidos e imágenes, así como videojuegos on-line u off-line donde las narrativas encuentran diferentes derivaciones que el jugador puede ir descubriendo paulatinamente, desarrollando ampliamente la historia originaria. No obstante, la principal aportación de Internet a la narrativa transmedia reside en la oportunidad que proporciona al lector de convertirse en autor de la propia historia, de dejar de ser un mero consumidor de información, para llegar a ser él mismo un generador individual o colectivo de historias. La web 2.0 y las redes sociales posibilitan este cambio en el rol del internauta fomentando la interactividad, la comunicación social y la participación ciudadana. Ahora bien, esta característica puede quedarse en una novedosa peculiaridad tecnológica o puede concebirse como una oportunidad para la educación para la ciudadanía. Tal es el sentido de nuestra propuesta, a propósito de la tragedia 
griega de Antígona, desde la cual es posible generar oportunidades para el diálogo y el análisis crítico de las diferentes cuestiones y personajes que aparecen en ella. Concretamente, mediante la creación de un recurso accesible on-line en el que los estudiantes puedan realizar las siguientes actividades:

a) Acceso ubicuo a la obra clásica -tanto a Antígona como a otras similares-, así como a extractos seleccionados de textos que permitan analizar, comprender y reflexionar sobre situaciones especialmente significativas, tomando postura razonada y argumentada sobre los conceptos más relevantes suscitados en la obra, en nuestro caso el lugar de lo privado, lo comunitario y lo público, así como diversas formas de articular la desobediencia civil dentro de los límites de los principios de la democracia liberal (Levinson, 2015).

b) Participar activamente en un diálogo sobre las cuestiones problemáticas a través de herramientas accesibles como los post, los chats o los foros. Un diálogo on-line que puede convertirse en intercultural (Panikkar, 1990) en tiempo real en la medida en que la experiencia no se desarrolla exclusivamente en una única aula, sino que es susceptible de llevarse a cabo en centros educativos de diferentes lugares del mundo. Además, este diálogo posibilita no sólo la concurrencia de perspectivas variadas sobre el tema tratado, sino que es capaz de incorporar lenguajes diversos audiovisuales propios del entorno virtual (Burbules, 2006), convirtiendo a los alumnos en creadores de narrativas transmedia.

c) Relacionar lo acontecido en Antígona con problemas actuales de ciudadanía, estableciendo semejanzas y diferencias y trasladando el análisis desde cuestiones históricas a situaciones recientes, posibilitando al alumno participar como agente de la vida cívica y abriendo la escuela al entorno y el entorno a la escuela (Marchesi, 2007). La búsqueda de correlatos actuales en el ciberespacio se nos presenta con múltiples posibilidades, en cuanto al formato -videos, imágenes, sonidos, textos, etc.-; la fuente de información -organismos públicos, organizaciones no gubernamentales, agencias de noticias, ciudadanos anónimos que participan en las redes sociales o escriben en sus propios blogs desde cualquier lugar del planeta-, o el problema reportado - desde cotidianos conflictos familiares, vecinales o locales, hasta cuestiones de mayor calado social y político nacional o global-.

d) Adoptar el rol de los diferentes personajes a través de la redacción de blogs de cada uno de ellos - por ejemplo, Antígona, Creonte, Ismena, Hemón o el pueblo- que permitan comprender los diferentes intereses de las posiciones enfrentadas en el conflicto y las razones de sus comportamientos en cada momento de la narrativa. Asimismo, el formato blog posibilita que los compañeros puedan plantear cuestiones a los personajes y que sean los mismos alumnos asignados al personaje quienes respondan a las preguntas. Esta actividad, en conjunción con la anterior y con la siguiente, permite superar parcialmente algunas de las principales críticas realizadas 
a la propuesta de desarrollo moral de Kolhberg desde la perspectiva aristotélica, consistentes en atribuir a sus dilemas un excesivo cognitivismo que no necesariamente se traduce en un comportamiento consecuente (Barrio, 2007). Además, permiten salvar las objeciones que advierten de la excepcionalidad o escasa relación de los dilemas morales con la vida diaria de los adolescentes (Coleman y Hendry, 2003). Esto es así porque los alumnos no sólo se enfrentan a un dilema individual o colectivamente, sino que pueden adoptar el rol concreto del personaje y vincularlo a situaciones actuales, cercanas en el tiempo y, en la medida de lo posible, significativas para ellos.

e) Profundizando en el sentido de la narrativa transmedia, tal y como la hemos definido aquí, es positivo posibilitar a los jóvenes que participen de la narración de manera activa, reescribiendo la historia de Antígona y Creonte, proponiendo un final alternativo que, presentando las razones que sustenten su decisión, constituya a su juicio el desenlace más justo y potencie su creatividad ética y política. Junto a ello, es pedagógicamente relevante que los alumnos no realicen esta actividad en un papel de forma individual, sino que se realice en colaboración con otros y la suban a Internet para que sea sometida al juicio de sus compañeros, descubriendo así diferentes perspectivas y argumentos sobre la misma cuestión. Esta metodología se inserta en el paradigma de la filosofía para niños donde los alumnos deben detectar un problema de carácter filosófico y plantear soluciones que consideren adecuadas.

Una aplicación piloto de esta propuesta pedagógica se ha llevado a cabo en un colegio de la ciudad de Santiago de Chile, con un grupo de alumnos de tercero medio, que corresponde en España al primer curso de Bachillerato. Como experiencia previa, realizamos el proyecto con un único grupo de estudiantes, por lo que no tenemos todavía la experiencia del diálogo entre diferentes centros en contextos diversos. Participaron alrededor de treinta y cinco adolescentes durante cuatro semanas de trabajo, guiados por un profesor en prácticas implicado en el proyecto. Presentamos a los alumnos un blog, diseñado según las pautas indicadas anteriormente, que recibió, hasta el momento del cierre de la actividad, 956 visitas y 40 comentarios. Los comentarios fueron realizados por los siete grupos de alumnos en los que se dividió la clase, discutiéndolos previamente en el seno del grupo en el aula.

Los estudiantes que asisten a este centro no cuentan con un uso habitual de las TIC en la escuela, lo que supuso un atractivo por su novedad, pero también una dificultad para su manejo ágil. Aun así, se observó que se sentían dueños de sus comentarios, incluso más que cuando realizan un trabajo directamente para el profesor, ya que estos comentarios podían ser vistos por sus compañeros. Esto les permitió sentirse más directamente implicados en el debate de sus ideas con el grupo de trabajo y el grupo de clase. Según una encuesta final, individual y libre, lo 
que les resultó más satisfactorio de la experiencia fue poder relacionar lo leído en una obra clásica con la realidad actual, pudiendo profundizar así en los problemas de la sociedad en la que viven. La opción de subir al blog noticias elegidas por ellos facilitó compartir la opinión sobre las mismas. Por otro lado, la posibilidad de proponer finales alternativos a la obra de Sófocles supuso la necesidad de poner en juego su creatividad ético-político-social, sometida al juicio, debate y valoración de los compañeros y el profesor, lo que les forzaba a argumentar consistentemente su postura. En las construcciones que propusieron de un final alternativo de la tragedia griega, se puede observar:

- Un mayor diálogo entre los personajes y posturas más intermedias a las planteadas por Sófocles.

- La capacidad de convencimiento de argumentos a través del diálogo.

- La asunción de las propias responsabilidades éticas y de las consecuencias de las propias acciones.

- La distinción de los planos de lo privado y lo público, aunque en algunos comentarios se observaba cierta confusión.

- La capacidad para reconocer no sólo las propias reivindicaciones, sino las de otros aunque sean claramente diferentes a las propias.

- En general, los adolescentes del proyecto se manifiestan más identificados con el personaje de Antígona y, en segundo lugar, con Hemón, lo que plantea cierta perspectiva de género en la lectura que hicieron de la obra.

La puesta en práctica del proyecto tropezó con algunos obstáculos, como la ya mencionada falta de uso habitual de las Tics en el centro o la dificultad de insertar una unidad didáctica en un programa de contenido cerrado propuesto por el Ministerio y ya consolidado en la institución, si bien el interés del docente permitió relacionar nuestra propuesta con los contenidos del programa y hacerla posible. Así mismo, inicialmente detectamos cierta resistencia de los estudiantes a poner sus comentarios en un blog, ya que, en la línea apuntada por el estudio de Pew Research Center a que antes nos referíamos, les preocupaba que sus comentarios quedaran registrados y pudieran ser vistos por otros agentes educativos que ellos no conocían. Sin embargo, posteriormente, valoraron positivamente la libertad de publicación de estos comentarios. Experimentaban la libertad de "jugar" con sus opiniones y trabajar de forma creativa las distintas actividades, llevando la interpretación de la desobediencia civil a distintos planos de gran significado para ellos. Una vez finalizada la experiencia, destacaron especialmente de la misma:

- La posibilidad de reflexionar libremente sobre la realidad sociopolítica actual.

- La interacción entre diferentes perspectivas acerca de un mismo problema.

- La clarificación de su propia postura y sus prioridades ante las problemáticas actuales. 


\section{CONCLUSIÓN}

La apropiación pedagógica de los entornos virtuales no sólo nos permite articular nuevas vías de comunicación y de acceso rápido y autónomo a la información, así como nuevos entornos de aprendizaje ubicuo. El uso cotidiano de las TIC nos descubre, además, nuevas oportunidades de participación ciudadana que reclaman la atención de los educadores, por su potencial para la formación cívica de los estudiantes. Los movimientos sociales de los últimos años han incorporado la tecnología como un elemento capaz de contribuir a la organización democrática. Sin embargo, los nuevos procesos no están exentos de riesgos que paradójicamente pueden desembocar en una incomunicación entre los diferentes agentes.

Desde la escuela, aprovechando las características de las TIC es posible -y necesario- promover una reflexión sobre nociones clave de la ciudadanía. La tragedia griega Antígona suscita de forma magistral la discusión en torno a la articulación de lo público y lo privado, y permite al alumno, en conjunción con las narrativas transmedia, tener una posición activa y participativa en el análisis, la reflexión y el diálogo sobre estos conceptos y sobre los problemas actuales que actualizan la obra sofóclea.

En un sentido positivo, Antígona puede ser leída no sólo como manifestación de una ausencia, sino también como expresión, a partir de las consecuencias a que lleva la falta de diálogo, de un germen de iteración entre los criterios instituidos en la esfera pública y las aspiraciones del espacio privado. Antígona, el personaje, comprende y acata finalmente el castigo que le corresponde en las leyes de los hombres y, camino a su muerte, el temor y la vacilación toman el lugar de la altivez y la seguridad iniciales. Exclama:

En tal abandono de amigos, infortunada, me encamino viva a los sepulcros de los muertos. Y ¿qué derecho divino he transgredido? Mas ¿por qué he de poner, desdichada de mí, mi vista aún en los dioses? ¿A qué aliado puedo invocar? Ciertamente, con mi piedad me gané un trato impío. Si esto es lo justo entre los dioses, escarmentada podré reconocer que he errado. Pero si son éstos quienes yerran, ¡que no sufran ni más ni menos mal del que injustamente me hacen! (Sófocles, Antígona, 84).

Creonte, a su vez, rectifica su decisión inicial, movido por la ira de los dioses que le ha privado de su hijo y de su esposa. Cierra la obra el canto del coro: "Con mucho, la sensatez es la condición de la felicidad. En las relaciones con los dioses es preciso no cometer impiedad alguna. Las palabas jactanciosas de los soberbios, recibiendo como castigo grandes golpes, les enseñan en su vejez a ser cuerdos" (ibid., 108).

La pregunta decisiva es si desde la actual educación para la ciudadanía podemos contribuir a dar un nuevo final a las diferentes Antígonas que leemos en nuestros días, a nuestras actuales tragedias entre lo público y lo privado, para llegar a aportar una resolución no trágica a las mismas, que instaure la conversación como principio. El proyecto cuyas bases teóricas hemos presentado aquí es un intento de 
promover esta posibilidad. Aunque en su puesta en práctica piloto sólo hayamos podido realizar una aproximación modesta a los objetivos planteados, entendemos que la experiencia ha sido suficientemente satisfactoria para probar las posibilidades de la escuela como un espacio de construcción de ciudadanía, espacio comunicativo del "entre", a través de la puesta en diálogo del legado clásico y los recursos tecnológicos modernos en el contexto de los problemas sociales actuales.

\section{REFERENCIAS BIBLIOGRÁFICAS}

ARENDT, H. (1993) La condición humana. Barcelona, Paidós.

ARENDT, H. (1996) La crisis en la educación, en Entre el pasado y el futuro. Barcelona, Península, $185-208$.

Bai, H. y CoHEn, A. (2014) Zen and the Art of Storytelling. Studies in Philosophy of Education, 33, 597-608. http://dx.doi.org/10.1007/s11217-014-9413-8

Balló, J. y Pérez, X. (2012) La desobediencia civil, en Sófocles, Antígona. Barcelona, Debolsillo, 109-140.

BARrio, J. M. (2007) Dimensiones del crecimiento humano. Educación y Educadores, 10 (1), 117-134.

BenHabiB, S. (1993) Feminist theory and Hannah Arendt's concept of public space. History of the Human Sciences, 6 (2), 97-114.

http://dx.doi.org/10.1177/095269519300600205

Benhabib, S. (2005) Los derechos de los otros: Extranjeros, residentes y ciudadanos. Barcelona, Gedisa.

Benhabib, S. (2006) Another Cosmopolitanism: Hospitality, Sovereignty, and Democratic Iterations. New York, Oxford University Press.

http://dx.doi.org/10.1093/acprof:oso/9780195183221.001.0001

BenhabiB, S. (2011) Dignity in Adversity: Human Rights in Troubled Times. Cambridge/ Malden, Polity Press.

Buber, M. (1981) ¿Qué es el hombre? México, FCE.

Burbules, N. C. (2006) Rethinking Dialogue in Networked Spaces. Cultural Studies - Critical Methodologies, 6 (1), 107-122.

http://dx.doi.org/10.1177/1532708605282817

ButLer, J. (2001) El grito de Antígona. Barcelona, El Roure.

Chomsky, N. (2012) Oсcupy. Londres, Penguin Books.

Coleman, J. C. y Hendry, L. B. (2003) Psicología de la adolescencia. Madrid, Morata.

Dalmau, M. (2012) El ocaso del pudor. Barcelona, Edhasa.

Dewey, J. (1995) Democracia y educación. Madrid, Morata.

Doueini, M. (2012) ¿Qué es el humanismo digital?, en Champeu, D. e INNERARity, D. (comps.) Internet y el futuro de la democracia. Barcelona, Paidós, 201-209.

Hampton, K. N.; Rainie, L.; Lu, W.; Dwyer, M.; Shin, I. y Purcell, K. (2014) Social Media and the "Spiral of Silence". Washington, Pew Research Center.

Hegel, G. W. F. (1989) Lecciones sobre la estética. Madrid, Akal.

Hernández, E.; Robles, M. C. y Martínez, J. B. (2013) Jóvenes interactivos y culturas cívicas: sentido educativo, mediático y político del 15M. Comunicar, XX, 40, 59-67. 
INNERARITY, D. (2012) Desenredar una ilusión: Notas para una teoría crítica de la democracia digital, en Champeu, D. e InNeRARITy, D. (comps.) Internet y el futuro de la democracia. Barcelona, Paidós, 37-43.

JENkins, H. (2010) Transmedia Storytelling and Entertainment: An annotated syllabus. Journal of Media \& Cultural Studies, 24 (6), December, 943-958. http://dx.doi.org/10.1080/10304312.2010.510599

Jover, G.; Belando-Montoro, M. R. y Guío, Y. (2014) The Political Response of Spanish Youth to the Socio-Economic Crisis: Some Implications for Citizenship Education. Journal of Social Science Education, 13 (3), 4-12.

Levinson, M. (2015) A Citizen for all seasons? The Promises and Perils of a Trans-Ideological Vision of Civic Empowerment. Social Philosophy Today, 31, 1-8.

MARCHeSI, A. (2007) Sobre el bienestar de los docentes: competencias, emociones y valores. Madrid, Alianza.

Morozov, E. (2012) El desengaño de Internet. Los mitos de la libertad en la red. Barcelona, Destino.

Noddings, N. (2009) La educación moral. Propuesta alternativa para la educación del carácter. Buenos Aires, Amorrortu.

Nussbaum, M. (2013) Political Emotions: Why Love Matters for Justice. Harvard University Press.

PANiKKar, R. (1990) Sobre el diálogo intercultural. Salamanca, San Esteban.

Prensky, M. (2001) Digital Natives, Digital Immigrants. On the Horizon, 9 (5), 1-6.

http://dx.doi.org/10.1108/10748120110424816 http://dx.doi.org/10.1108/10748120110424843

Ramírez García, A.; Renés Arellano, P. y García Ruiz, M. R. (2014) Presencia de la competencia mediática en los objetivos curriculares de la etapa de educación primaria. Teoría de la Educación. Revista Interuniversitaria, 26 (1), 137-159. http://dx.doi.org/10.14201/teoredu2014261137159

Salzani, C. (2006) Figures of Commonality in Sophocles' Antigone. Colloquy: Text Theory Critique, 11, 8-30.

Santamaría, A. L. (2009) Implicaciones éticas de la 'Antígona' de Sófocles: una reflexión sobre el pensamiento trágico griego. Madrid, Plaza y Valdés. http://dx.doi.org/10.5211/9788492751204

SASSEN, S. (2011). The City: Its Return as a Lens into Larger Economic and Technological Histories. Conferencia principal. European Conference on Educational Research. Berlín.

Sófocles (2012) Antígona. Barcelona, Debolsillo.

Steiner, G. (2000) Antígonas. La travesía de un mito universal por la historia de Occidente. Barcelona, Gedisa.

UNESCO (2011) Media and Information Literacy Curriculum for Teachers. Paris, UNESCO. Consultado el 16 de septiembre de 2014. http://www.unesco.org/new/es/communicationand-information/resources/publications-and-communication-materials/publications/ full-list/media-and-information-literacy-curriculum-for-teachers/.

Zappulla, S. (2011) Reading Antigone through Hannah Arendt's political philosophy, en Alcaraz, M. J.; Carrasco, M. y Rubio, S. (eds.) Art, Emotion and Value. Proceedings of the 5th Mediterranean Congress of Aesthetics. Cartagena, Universidad de Murcia y Universidad Politécnica de Cartagena, 111-137. 